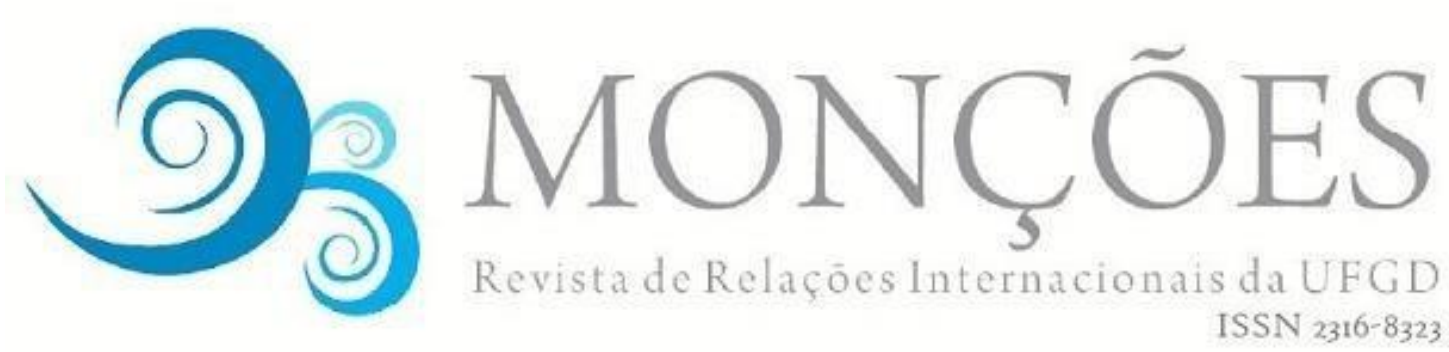

\title{
MENSURANDO EMPODERAMENTO: UMA ANÁLISE DOS ÍNDICES DE DESIGUALDADE DE GÊNERO PROPOSTOS PELO PROGRAMA DAS NAÇÕES UNIDAS PARA O DESENVOLVIMENTO
}

\author{
MANUELLA RIANE AZEVEDO DONATO \\ Doutoranda em Sociologia pela Universidade Federal de Pernambuco (UFPE) \\ Professora no Centro Universitário Tabosa de Almeida (ASCES-UNITA)
}

\begin{abstract}
RESUMO: A progressiva incorporação da concepção de empoderamento às políticas para mulheres promovidas pelas agências internacionais de desenvolvimento parece afastar-se de abordagens feministas que defendem o empoderamento como pilar fundamental para a transformação das relações de gênero. Nesse contexto, a mensuração quantificável de resultados políticos apresenta-se como estratégia de operacionalização de conceitos tão complexos como o de empoderamento por parte de organizações internacionais. O objetivo deste trabalho é analisar como é utilizada a concepção de empoderamento para medir as desigualdades de gênero nos índices globais propostos pelo Programa das Nações Unidas para o Desenvolvimento.
\end{abstract}

PALAVRAS-CHAVE: Empoderamento; Índices; PNUD.

\section{MEASURING EMPOWERMENT: AN ANALYSIS OF GENDER INEQUALITY INDICES PROPOSED BY UNITED NATIONS DEVELOPMENT PROGRAMME}

\begin{abstract}
The progressive incorporation of the concept of empowerment into women's policies promoted by international agencies for development seems to distance itself from feminist approaches that defend empowerment as a fundamental pillar for the transformation of gender relations. In that context, using quantifiable measurements of policy outcomes is presented as a strategy for operationalizing concepts as complex as empowerment by international organizations. The purpose of this article is to analyze how the concept of empowerment is used to measure gender inequalities in the global indices proposed by United Nations Development Programme.
\end{abstract}

KEYWORDS: Empowerment; Indices; UNDP. 


\section{Introdução}

Este trabalho parte da percepção de que a ampliação do uso do conceito de empoderamento por parte de organismos políticos nacionais e internacionais parece se afastar de abordagens feministas que defendem tal conceito como pilar fundamental para a transformação das relações de gênero.

A partir da observação da crescente influência da política internacional para o desenvolvimento de políticas públicas nacionais e, nesse contexto, a relevância dada a rankings propostos por agências internacionais para a avaliação dos progressos realizados pelos Estados, busca-se compreender de que maneira um conceito tão complexo como o de empoderamento tem sido utilizado para o monitoramento das políticas implementadas.

Identifica-se que os índices propostos pelo Programa das Nações Unidas para o Desenvolvimento (PNUD) figuram como as principais referências internacionais na mensuração das desigualdades de gênero e empoderamento das mulheres. São eles o Gender-related Development Index (GDI), o Gender Empowerment Measure (GEM) e o Gender Inequality Index (GII) ${ }^{1}$.

Assim, com o objetivo de compreender de que maneira o PNUD utiliza a concepção de empoderamento para medir as desigualdades de gênero, buscase, primeiramente, apresentar diferentes perspectivas feministas sobre 0 conceito de poder, entre as quais a concepção de poder como empoderamento, para então percorrer a trajetória de incorporação do conceito de empoderamento às discussões internacionais sobre direitos das mulheres, gênero $e$ desenvolvimento. Em seguida, identifica-se quais são os elementos utilizados para a composição dos índices de desigualdade de gênero no que se refere a empoderamento. E, por fim, são analisadas as limitações apontadas aos índices de desigualdades de gênero propostos pelo PNUD, quanto à mensuração do empoderamento das mulheres.

Dessa forma, espera-se contribuir para o debate acerca dos limites e possibilidades da incorporação de concepções feministas no âmbito tradicional da política internacional.

\footnotetext{
${ }^{1}$ São utilizadas as nomenclaturas em inglês, em função da falta de uniformidade encontrada com relação às traduções dos referidos índices, mesmo nas fontes oficiais do PNUD.
} 


\section{Perspectivas feministas sobre o conceito de poder}

O conceito de poder aparece na teoria feminista, explícita ou implicitamente, sob três formas distintas: poder como recurso, poder como dominação e poder como empoderamento (ALLEN, 1998). Essa classificação se divide em poder sobre, poder para, ou uma utilização integrada de ambas (SQUIRES, 1999). O poder como recurso e poder como dominação são compreendidos como formas de poder sobre, do ponto de vista individual e estrutural, respectivamente. No que se refere à categoria de poder para, na qual se enquadraria o poder como empoderamento, Vázquez (2013b) propõe duas vertentes de análise, quais sejam poder como cuidado e poder como liberdade feminina. A partir dessas denominações é possível analisar as formas pelas quais as diferentes correntes do feminismo ${ }^{2}$ compreendem e utilizam a noção de poder.

A ideia do poder como recurso está presente nas teorias feministas liberais e, nessa perspectiva, o poder é entendido como um bem social fundamental. Portanto, o enfoque dado na análise do poder é sobre sua distribuição entre os membros da sociedade, particularmente na medida em que as mulheres acessam esse recurso, em comparação aos homens. No âmbito das políticas públicas, essa é uma abordagem bastante disseminada, dada a sua natureza mensurável e voltada à resolução de problemas. Um exemplo dessa abordagem é o entendimento de que a distribuição de assentos políticos de forma equitativa entre homens e mulheres funciona como uma maneira de distribuir o poder de forma justa em uma dada instituição política (VÁZQUEZ, 2013b).

Enquanto para as feministas liberais o poder é um recurso que deve ser distribuído para garantir uma forma de justiça, as feministas radicais ${ }^{3}$ defendem

\footnotetext{
2 Vale destacar que a agenda feminista é marcada por tensões que refletem não somente diferentes abordagens teóricas mas também relações marcadas por posições desiguais de poder. Sobre a trajetória histórica dos movimentos teóricos e políticos do feminismo, ver Kroløkke e Sørensen (2006).

${ }^{3}$ A distinção entre feminismo radical, feminismo liberal e feminismo marxista diz respeito a correntes teóricas clássicas do feminismo.
} 
que somente é possível haver justiça pondo fim aos processos de dominação. Nessa perspectiva, o poder, que é entendido como dominação, apresenta-se como um fenômeno sistêmico não desejável, que representa a estrutura masculina dominante, ou seja, o patriarcado. Vázquez (2013a) afirma que é possível identificar atualmente uma forte influência dessa abordagem em certos movimentos feministas e, em alguns casos, na legislação vigente. Um exemplo disso é a Lei de Violência de Gênero da Espanha, que considera todo casal heterossexual como um ambiente de potencial dominação masculina e, por isso, qualquer ato violento de um homem contra uma mulher em relação conjugal deve ser punido como violência de gênero. Nesse sentido, as mulheres são entendidas como uma categoria universal de pessoas oprimidas pelo sistema de dominação patriarcal.

O feminismo socialista também se utiliza da abordagem do poder como dominação. De forma geral, há divergências com as feministas radicais em torno do conceito de patriarcado, sobre em que medida ele regula todas as relações sociais ou atua articuladamente com o capitalismo. Essa discussão remete ao entendimento sobre a forma com que o poder opera, entre uma base econômica ou simbólica e cultural (VÁZQUEZ, 2013b).

Embora a abordagem de poder sobre, que pressupõe o entendimento do poder como recurso ou como dominação, tenha ocupado um lugar hegemônico nas análises feministas, é possível identificar elaborações teóricas que buscam um paradigma alternativo de poder, com vistas à construção de relações políticas a partir de uma base feminista. A ideia de poder como cuidado refere-se às abordagens que defendem a reelaboração do conceito de poder a partir das experiências das mulheres, e coloca-se como um desafio epistemológico e prático aos vieses androcêntricos da teoria política (VÁZQUEZ, 2013b). As experiências das mulheres poderiam conduzir ao desenvolvimento de outros formatos de liderança, por exemplo, ou mesmo trazer a lógica do âmbito da reprodução para as esferas da produtividade. Trata-se, portanto, de um entendimento de poder como capacidade de transformação de realidades (HARTSOCK, 1983).

O poder como liberdade feminina baseia-se na concepção de poder para como um significante vazio, que deve ser desenvolvido a partir das relações 
entre as mulheres e de suas experiências. Trata-se de uma perspectiva amplamente presente em grupos feministas exclusivos para mulheres e que buscam construir uma esfera pública alternativa baseada nas relações femininas e livres das normas e categorias androcêntricas. Vázquez (2013b) atribui a Hannah Arendt uma importante influência nessa abordagem, a partir da sua concepção de poder como a habilidade de atuar conjuntamente, de forma nãoinstrumental e oposta à violência. O poder como liberdade feminina não se trata de um fenômeno sistêmico ou individual, mas de um processo relacional. $O$ relacionamento interpessoal de confiança mútua tem, assim, consequências políticas e permite a construção de uma identidade, bem como o estabelecimento de novas bases epistemológicas necessárias para 0 empoderamento.

As abordagens apresentadas são desenvolvidas sobretudo no marco da segunda onda do feminismo. Durante a década de 1970, poder figurou como categoria central para a teoria feminista radical. Ao longo da década de 1980, é possível observar duas grandes tendências: por um lado, algumas correntes rejeitavam a noção de poder como um todo; por outro lado, identifica-se uma mudança no debate de poder para o enfoque sobre justiça, com maior atenção a temas relacionados a igualdades e diferenças, esfera pública, redistribuição e reconhecimento ${ }^{4}$. Com a emergência da terceira onda do feminismo, as categorias de poder foram revisitadas e receberam contribuições a partir das correntes estabelecidas.

O principal desafio apresentado à concepção de poder como recurso trata-se da reificação do poder, que parece induzir a uma percepção estática sobre ele, sem considerar o contexto estrutural e as relações específicas em que foi produzido. Além disso, a esfera pública aparece, nessa abordagem, como um lugar neutro a partir do qual é possível regular as condições vivenciadas pelas mulheres, o que demonstra um excessivo otimismo com relação à estrutura de cidadania (VÁZQUEZ, 2013b).

\footnotetext{
${ }^{4}$ Sobre a perspectiva de justiça com base em reconhecimento e redistribuição, ver Fraser (2002; 2006).
} 
A ideia de poder como dominação e o próprio conceito de patriarcado foram criticados por subestimar o papel de agência e atribuir às mulheres um lugar essencializado e vitimizado, sem uma aparente proposta de transformação. Com base nisso, o conceito de patriarcado é retomado não como uma constante histórica, mas como um conjunto de instituições e estruturas que remete a um sistema de relações sociais articulado com o capitalismo e o racismo. Essa concepção sistêmica propõe pensar nas intersecções entre os diferentes eixos de subordinação e também sobre a posição dominante que algumas mulheres podem ter sobre outras, ou mesmo sobre alguns homens. Nesse sentido, as abordagens feministas pós-coloniais destacam-se como a corrente teórica que retoma explicitamente o marco metateórico do poder para tratar da situação das mulheres. Entre suas contribuições, apontaram as feministas brancas do Norte global como sujeitos dominantes e trouxeram novas categorias para pensar a dominação, a exemplo do conceito de subalternidade. Esta é uma concepção que propõe pensar a dominação epistêmica juntamente com a exploração material, ao mesmo tempo em que busca desnaturalizar a suposta homogeneidade das mulheres do Sul global, que convencionalmente ocupam o lugar do "outro" na teoria feminista hegemônica, construída a partir do sujeito dominante (LUGONES, 2008; SPIVAK; 2010).

Além disso, os feminismos pós-coloniais conectaram as perspectivas de poder sobre e poder para, por meio da identificação de formas de resistência à subalternidade. Nesse sentido, desafiam as concepções ocidentais de um sujeito político racional e de identidade fixada e, no que se refere à abordagem de poder como liberdade feminina, desconstroem a perspectiva ocidental que vincula a ideia de agência à liberdade do sujeito. Vale ressaltar, contudo, que os principais desafios à concepção de poder como liberdade feminina foram apresentados pelos estudos sobre performatividade de gênero, de Judith Butler (2009).

Entre as contribuições em torno da abordagem de poder como cuidado, destaca-se a crítica de que ela subestima o impacto do poder sobre, ao considerar que as práticas de cuidado e as relações entre as mulheres podem ser suficientes, sem necessariamente recorrer a instrumentos que reconheçam e subvertam a dominação (VÁZQUEZ 2013a). Nesse sentido, a noção de empoderamento passa a ser utilizada pelas feministas do Sul Global como uma 
noção de poder que dialoga com a ideia do poder como cuidado e tem na experiência reprodutiva uma base para a ação política. Dessa forma, o empoderamento das mulheres é considerado como um processo que diz respeito tanto a agência individual - ainda que baseada em experiências coletivas - quanto a transformação social, e envolve elementos culturais, ambientais, sociais, econômicos e políticos.

O conceito de empoderamento ganha espaço tanto como uma perspectiva feminista de poder que integra a práxis de movimentos organizados, bem como do ponto de vista de análises teóricas, a partir de diferentes abordagens. Nesse contexto, a categoria de empoderamento passa a ser amplamente utilizada nos discursos relacionados à agenda de gênero e desenvolvimento (SARDENBERG, 2009a). Nas seções que seguem, busca-se compreender em que medida a tendência de incorporação da noção de empoderamento das mulheres na política internacional de desenvolvimento aproxima-se ou afasta-se da discussão feminista em torno das diferentes concepções de poder.

\title{
Sobre a utilização da concepção de empoderamento
}

O ponto de partida para esta discussão em torno da utilização da concepção de empoderamento ancora-se na diversidade de significados atribuídos a este importante elemento do pensamento feminista, quando transferido para as esferas institucionais. A utilização disseminada do conceito de empoderamento como resultado a ser atingido pelas políticas públicas amplia-se sobretudo no âmbito dos discursos de desenvolvimento.

\begin{abstract}
Isso significa que assim como conceitos cunhados pelo feminismo, como gênero, por exemplo, têm sido apropriados e ressignificados no discurso de desenvolvimento, as agendas e conceitos de desenvolvimento têm também permeado o pensamento feminista sobre empoderamento das mulheres, tornando difícil definir uma linha entre os dois (SARDENBERG, 2009a, p.5) .
\end{abstract}

\footnotetext{
5 Texto original: "This means that just as feminist-coined concepts, such as 'gender' for instance, have been appropriated and re-signified in development discourse, so too development agendas and concepts have permeated feminist thinking about women's empowerment, making it difficult to draw the line between the two".
} 
Como consequência da apropriação do termo empoderamento por diversos atores políticos, entre os quais não há um consenso estabelecido sobre seu entendimento, percebe-se a adoção de diferentes significados a partir de seu uso de forma indiscriminada. Como afirma Srilatha Batliwala (1994, p.1), empoderamento "é um dos termos mais amplamente utilizados no léxico do desenvolvimento, significando coisas diferentes para pessoas diferentes - ou, o que é mais perigoso - todas as coisas para todas as pessoas"6.

\begin{abstract}
Nem mesmo entre as diferentes agências de cooperação internacional existe consenso quanto ao que seja empoderamento, tampouco no que se refere aos processos e ações que, de fato, contribuem para tanto, e quais indicadores nos instrumentam melhor na mensuração e avaliação desse processo em instâncias específicas (SARDENBERG, 2009b, p.1).
\end{abstract}

Há uma certa desconfiança em relação ao uso da expressão empoderamento, segundo Cecília Sardenberg (2009a), em especial por parte de feministas latino-americanas. Isso ocorre justamente em função da apropriação do conceito por parte de agências e organizações internacionais, bem como por governos nacionais e locais, com o intuito de legitimar suas práticas e políticas "que, em uma perspectiva feminista, estão longe de ser realmente empoderadoras para as mulheres" (SARDENBERG, 2009a, p.4) ${ }^{7}$.

Embora sejam diversas as correntes feministas e, portanto, também diversas as concepções feministas acerca de empoderamento das mulheres, entende-se que é possível identificar alguns elementos que permitem distinguir as abordagens feministas em torno da noção de empoderamento. Nesse sentido, Sardenberg (2009a) identifica duas grandes abordagens conceituais sobre empoderamento, definidas como empoderamento liberal e empoderamento libertador ${ }^{8}$.

A abordagem liberal concebe o empoderamento das mulheres como um instrumento para a o desenvolvimento, algo que contribui para alcançar suas prioridades de, por exemplo, redução da pobreza ou fortalecimento da democracia. Portanto, o foco do empoderamento na perspectiva liberal é o

\footnotetext{
6 Texto original: "is one of the most loosely-used terms in the development lexicon, meaning different things to different people - or, more dangerously, all things to all people".

7 Texto original: "that, from a feminist perspective, are far from being really empowering for women".

${ }^{8}$ Tradução livre de liberal empowerment e liberating empowerment, respectivamente.
} 
aspecto instrumental, de caráter técnico, que supostamente pode ser ensinado em cursos de formação, cada vez mais disseminados no formato das chamadas capacitações. Para Sardenberg (2009a), essa abordagem despolitiza o processo de empoderamento, na medida em que afasta de sua concepção as relações de poder.

Já para a abordagem do empoderamento libertador, as relações de poder constituem-se como elemento fundamental. Nessa perspectiva, o empoderamento diz respeito ao processo de construção de autonomia e autodeterminação das mulheres, bem como ao enfrentamento do patriarcado.

\begin{abstract}
Assim, empoderamento é simultaneamente um instrumento para transformação social e um fim em si mesmo, já que requer a libertação das mulheres das correntes da opressão de gênero. Desse modo, embora feministas também busquem acabar com a pobreza, com as guerras, e construir estados democráticos, nessa perspectiva feminista o maior objetivo do empoderamento das mulheres é questionar, desestabilizar e eventualmente transformar a ordem de gênero da dominação patriarcal (SARDENBERG, 2009a, p.5-6) .
\end{abstract}

A concepção do empoderamento libertador dialoga de maneira próxima com abordagens feministas latino-americanas. Estas, ao mesmo tempo em que reconhecem a importância do processo individual de empoderamento das mulheres, destacam o papel central da organização coletiva para a transformação das relações de poder (SARDENBERG, 2009a).

O questionamento das relações de poder estabelecidas e a construção de novas relações e formas de poder, está, portanto, na base da concepção feminista sobre empoderamento. Nesse sentido, o poder diz respeito à possibilidade de as mulheres tomarem decisões sobre suas próprias vidas, livres de opressões. Não se trata, portanto, de simplesmente redistribuir o poder dentro da estrutura existente, mas de transformar a própria estrutura.

\footnotetext{
9 Texto original: "Thus empowerment is simultaneously an instrument for social transformation and an end in and of itself, as it entails women's liberation from the chains of gender oppression. Thus, though feminists also aspire to end poverty, wars, and build democratic states, in this feminist perspective the major objective of women's empowerment is to question, destabilise and eventually transform the gender order of patriarchal domination".
} 
Incorporação do conceito de empoderamento às discussões internacionais sobre mulheres, gênero e desenvolvimento

O ano de 1975 foi declarado pela ONU como o Ano Internacional das Mulheres, e inaugurou a Década das Nações Unidas para as Mulheres, entre 1976 e 1985. Durante esse período, houve uma ampliação do debate sobre as desigualdades existentes entre homens e mulheres em todo o mundo e diversas pesquisas apontaram a necessidade de criação de mecanismos nacionais e internacionais de promoção das condições de vida das mulheres (TINKER; JAQUETE, 1987).

Entre as perspectivas teóricas e políticas presentes nas discussões acerca das desigualdades entre mulheres e homens na década de 1970, ganha força a abordagem que tem como enfoque a inserção das mulheres no campo do desenvolvimento, conhecida como Mulheres em Desenvolvimento (MED). A MED questiona a exclusão das mulheres dos processos de desenvolvimento, mais precisamente dos benefícios que deveriam decorrer dos avanços em termos de desenvolvimento econômico. Isso ocorre em função da invisibilização das mulheres como protagonistas do desenvolvimento, resultante, em grande medida, de sua marginalização dos processos produtivos (KABEER, 2003; SANTOS, 2014).

De acordo com Moser (1989), pode-se identificar cinco enfoques principais na implementação de políticas e projetos no campo do desenvolvimento voltados às mulheres, quais sejam: bem-estar, equidade, antipobreza, eficiência e empoderamento.

Nas estratégias de bem-estar levadas a cabo na década de 1950, quando os projetos de desenvolvimento se davam principalmente por meio de financiamento de obras de infraestrutura e capacidades produtivas, as mulheres eram vistas como mães e integrantes de grupos vulneráveis. Nessa perspectiva, as mulheres têm um papel reprodutor e de cuidado, sendo, portanto, as receptoras passivas do desenvolvimento, e não partes integrantes de sua constituição. Assim, as políticas e projetos para as mulheres eram voltados à capacitação em questões de nutrição e saúde, com destaque para as funções domésticas (ZABALA, 2006). 
Na década de 1970, destaca-se a adoção das estratégias de equidade e antipobreza, cuja principal contribuição é o reconhecimento e a visibilização do papel produtivo das mulheres como participantes do desenvolvimento e de sua importância para a superação da pobreza nos países do chamado Terceiro Mundo. Enquanto a estratégia de equidade está voltada a todas as mulheres de forma geral, com ênfase na educação e capacitação, a estratégia antipobreza centra-se nas mulheres em situação de pobreza, e atua a fim de gerar renda. Nesse contexto, vai sendo produzida uma mudança de perspectiva sobre a equidade, que deixa de ser um fim em si mesmo, para ser entendida como um meio para a eficiência (ZABALA, 2006).

Dessa maneira, a estratégia de eficiência percebe as mulheres como "un recurso infrautilizado" (ZABALA, 2006, p.12) importante para o processo de desenvolvimento. Vale salientar que tal enfoque é desenvolvido em um contexto de ajuste estrutural, no qual se busca reduzir os gastos do Estado. Assim, ao mesmo tempo em que se fomenta a participação das mulheres em um mercado de trabalho cada vez mais deteriorado, também se sobrecarrega o papel de cuidado doméstico, na medida em que os serviços sociais estatais vão sendo reduzidos.

É possível questionar em que medida as diferentes abordagens contribuem para a inclusão da igualdade de gênero como elemento fundamental do desenvolvimento. Nesse sentido, as perspectivas de empoderamento e desenvolvimento humano se somam como contribuições valiosas à agenda de desenvolvimento. Ainda que a ideia de empoderamento tenha sido adotada e adaptada pelas agências internacionais de forma diversa das perspectivas propostas pelos movimentos feministas, seus elementos de mobilização e agência, junto com a ideia de desenvolvimento humano, contribuíram para um enfoque menos utilitário e mais centrado nas pessoas (ZABALA, 2006).

Em meados da década de 1980, consolida-se a abordagem Gênero e Desenvolvimento (GED), que trata de avançar nas discussões sobre a relação entre as mulheres e o desenvolvimento, a partir de uma perspectiva feminista de gênero, que questiona as relações desiguais de poder entre homens e mulheres. Fortemente influenciada pelo enfoque de empoderamento, a GED "vê as mulheres como agentes de mudança no processo de desenvolvimento e salienta 
a importância da organização/mobilização feminina para a conquista de direitos" (SANTOS, 2014, p.31). Além disso, a GED problematiza a hierarquia existente entre as esferas produtiva e reprodutiva, bem como a divisão sexual do trabalho, e enfatiza a necessidade da participação do Estado na promoção de políticas públicas voltadas ao empoderamento das mulheres e a consequente transformação das relações de gênero.

É no contexto de fortalecimento da GED que ocorre a IV Conferência Mundial sobre as Mulheres, em Pequim, promovida pelas Nações Unidas em 1995. Na conferência, a transversalização de gênero ${ }^{10}$ foi reconhecida como estratégia para a efetividade das políticas, e o empoderamento das mulheres, como objetivo que permite a transformação das relações de gênero (ZABALA, 2006). Apesar dos compromissos assumidos em Pequim, a abordagem GED encontra resistências para sua adoção por parte dos governos nacionais, bem como de agências internacionais. Nesse sentido, percebe-se uma tendência de instrumentalização ${ }^{11}$ dos conceitos de gênero e empoderamento, de forma a aproximá-los aos enfoques de eficiência (SANTOS, 2014).

Diante do argumento de que a incorporação do conceito de empoderamento aos discursos das políticas de desenvolvimento resulta no afastamento das perspectivas dos movimentos feministas (KABEER, 2001), busca-se, nas seguintes seções, identificar os elementos utilizados para a composição dos índices de desigualdade de gênero propostos pelo PNUD, a fim de analisar suas contribuições e limitações no que diz respeito à mensuração do empoderamento das mulheres a partir de uma perspectiva feminista.

\section{Elementos utilizados para a composição dos índices de desigualdade de gênero}

\footnotetext{
${ }^{10}$ A transversalização de gênero "é uma estratégia para enfrentamento das desigualdades entre mulheres e homens na dimensão integrativa de implementação, monitoramento e avaliação de políticas e programas em todas as esferas políticas, econômicas e sociais com o objetivo da equidade de gênero" (SANTOS, 2014, p.32).

${ }^{11}$ Sobre a apropriação da agenda feminista pelas instituições internacionais, ver Fraser (2009).
} 
A construção de índices globais referentes às desigualdades de gênero apresenta-se como importante esforço no âmbito das políticas internacionais de desenvolvimento, porque propõe aferir lacunas existentes quanto a equidade de gênero de forma comparativa entre países, bem como avaliar avanços e obstáculos na elaboração e implementação de políticas adotadas ao redor do mundo. De acordo com Charmes e Wieringa (2003), os índices propostos pelo PNUD na década de 1990 surgem como os principais instrumentos construídos para o monitoramento de progressos no âmbito da igualdade de gênero e empoderamento das mulheres em escala mundial.

No entanto, a tradução dos conceitos de gênero, poder e empoderamento em processos mensuráveis constitui-se como desafio para instrumentos dessa natureza. Enquanto reconhece-se, por um lado, o impacto relevante que teve a criação desses índices, tanto na produção acadêmica, quanto no âmbito das políticas públicas (SCHULLER, 2006), por outro lado aponta-se a existência de muitas críticas devido a suas limitações conceituais e metodológicas (CHARMES; WIERINGA, 2003; PERMANYER, 2013).

Nesta seção serão apresentados os índices lançados em 1995, o GDI e o GEM, bem como o índice que os substituiu a partir de 2010, o Gll, resultante das críticas apresentadas aos primeiros. O objetivo é identificar as dimensões que foram consideradas para a elaboração dos índices propostos pelo PNUD para avaliar a situação global acerca das disparidades de gênero, com foco nos indicadores de empoderamento.

\section{Gender-related Development Index}

O GDI foi elaborado pelos economistas Sudhir Anand e Amartya Sen a partir das críticas feitas ao Índice de Desenvolvimento Humano (IDH), por este não levar em consideração as desigualdades existentes entre os grupos populacionais. A ideia central do GDI foi, portanto, gerar uma penalização do IDH quando houvesse disparidades de gênero em qualquer das três dimensões consideradas para sua medição, com base no argumento de que as desigualdades de gênero afetam o nível de bem-estar de um país de forma geral (BARDHAN; KLASEN, 2000).

Assim, quanto maior fosse a lacuna identificada entre mulheres e homens 
no que se refere aos indicadores de expectativa de vida, educação e renda, maior seria a diferença entre o GDI e o IDH. Por isso, o GDI não deve ser interpretado de forma independente do IDH, mas como o IDH descontado pelas desigualdades de gênero existentes, demonstrando, dessa forma, a perda de desenvolvimento humano resultante dessas inequidades.

Gender Empowerment Measure

A proposta do GEM, o segundo índice apresentado no Relatório de Desenvolvimento Humano de 1995, era avaliar em que medida as mulheres logram participar ativamente da vida política e econômica e fazer parte dos processos de tomada de decisões. Dessa maneira, enquanto o GDI tem como enfoque a expansão de capacidades, o GEM "está preocupado com o uso daquelas capacidades para obter vantagens nas oportunidades da vida" (UNDP, 1995, p.73) ${ }^{12}$.

As variáveis sobre as quais o GEM constrói sua medida de empoderamento das mulheres baseiam-se na participação política, econômica e profissional, com o intuito de "definir o quanto as mulheres têm sido empoderadas ou emancipadas para participar nos diversos aspectos da vida pública em comparação com os homens" (UNDP, 1995, p.73) $)^{13}$.

Embora a participação das mulheres possa ser analisada em diversas esferas, o PNUD (1995) justifica a escolha das variáveis com base na disponibilidade de dados, e reconhece que muitos aspectos relevantes do empoderamento das mulheres não são integrados ao GEM, especialmente do âmbito doméstico, da vida comunitária e áreas rurais. A avaliação global do empoderamento das mulheres proposta pelo GEM é, portanto, realizada a partir de três indicadores: i) acesso a renda, ii) oportunidades profissionais e participação em decisões econômicas e iii) oportunidades políticas e participação em decisões políticas.

O indicador de acesso a renda busca demonstrar a existência de poder sobre recursos econômicos, e é mensurado a partir da renda per capita

\footnotetext{
12 Texto original: "is concerned with the use of those capabilities to take advantage of the opportunities of life".

${ }^{13}$ Texto original: "to determine how much women have been empowered or enfranchised to take part in different aspects of public life in comparison with men".
} 
desagregada por sexo. Diferente da variável de renda proposta no GDI, cuja relevância diz respeito à contribuição direta para o desenvolvimento humano a partir da redução da pobreza e seus desdobramentos, no GEM a renda é analisada como fonte de poder, partindo-se do pressuposto de que permite às mulheres maior autonomia para fazer escolhas (UNDP, 1995).

$O$ indicador de oportunidades profissionais e participação em decisões econômicas baseia-se no desempenho por mulheres de trabalhos classificados como profissionais, técnicos, administrativos ou gerenciais. Enquanto os trabalhos classificados como profissionais ou técnicos são entendidos como oportunidades de desenvolvimento de carreira, os trabalhos administrativos ou gerenciais representam uma maior aproximação de processos decisórios (UNDP, 1995).

O indicador de oportunidades políticas e participação em decisões políticas é avaliado pela variável de representação das mulheres no parlamento, medida pela proporcionalidade dos assentos ocupados na esfera nacional. De acordo com o PNUD (1995), um dos melhores indicadores para avaliar a participação política das mulheres seria a proporcionalidade da representação nos organismos locais, na esfera municipal; no entanto, muitos países não dispõem de dados dessa natureza, o que inviabilizaria tal medida.

Os três indicadores em que se baseia o GEM são valorados de forma equitativa para a constituição do índice, que buscou, dessa forma, avaliar resultados sobre participação política e econômica das mulheres, e dar indicações "do quanto as mulheres estão empoderadas nessas esferas em diferentes países" (UNDP, 1995, p.72) ${ }^{14}$.

A disponibilidade, bem como o refinamento, dos dados para a constituição dos indicadores é apontada como uma necessidade para a expansão da cobertura nas três dimensões utilizadas para a formulação do GEM, que em seu primeiro ano foi avaliado para 116 países (UNDP, 1995).

Ao longo dos quinze anos que seguem ao seu lançamento, o GEM assim como o GDI foram temas de discussões políticas e acadêmicas, a partir das quais foram levantadas críticas relevantes quanto a seus aspectos

14 Texto original: "of how much women are empowered in these spheres in different countries". 
metodológicos e constitutivos. Esse processo foi fomentado pelo próprio PNUD com a realização de uma série de reuniões de grupos de experts organizadas com o objetivo de reformar o GDI e o GEM (BETETA, 2006) e culminou em 2010 com o lançamento do Gll no Relatório de Desenvolvimento Humano (UNDP, 2010).

Gender Inequality Index

O Gll foi formulado no intuito de superar as principais limitações apontadas ao GDI e ao GEM. Para isso, foram propostas novas dimensões que permitissem avaliar as desigualdades de gênero, bem como um novo formato para integrar informações multidimensionais de maneira que possibilitasse uma utilização comparativa entre as performances dos diferentes países ao longo do tempo (PERMANYER, 2013).

Foram definidas três dimensões para a formulação do Gll, levando em consideração as possibilidades e limitações existentes quanto à relevância dos dados disponíveis e sua abrangência em termos de cobertura geográfica. Assim, quando de seu lançamento em 2010, o Gll foi calculado para 138 países, com base em três dimensões: saúde reprodutiva, mercado de trabalho e empoderamento (KLASEN; SCHULLER, 2011; PERMANYER, 2013).

A saúde reprodutiva foi incluída pela primeira vez como uma dimensão constituinte dos índices de desenvolvimento e desigualdade de gênero propostos até então. Os indicadores utilizados para avaliar essa dimensão são as taxas de mortalidade materna e de fertilidade das adolescentes. Enquanto a primeira é medida pelo número de mortes de mulheres a cada 100.000 nascimentos, a última refere-se ao número de nascimentos por cada 1.000 mulheres em idade entre 15 e 19 anos (PERMANYER, 2013; UNDP, 2010).

De acordo com o PNUD (2010), uma taxa de mortalidade materna reduzida é uma indicação consistente da situação das mulheres em uma sociedade, posto que há um baixo risco de morte durante o parto quando existe um contexto em que o serviço à saúde da mulher é de qualidade, assim como outros elementos fundamentais, como educação básica, nutrição e habitação.

Já a taxa de fertilidade das adolescentes pode refletir as dificuldades de acesso a educação básica, a serviços de saúde sexual e planejamento 
reprodutivo, entre outras barreiras para a garantia de direitos. Para o PNUD (2010), está associada a riscos maiores para a saúde da mulher adolescente, além de dificultar seu acesso à educação e a inserção qualificada no mercado de trabalho.

Uma segunda dimensão considerada para o Gll é a participação no mercado de trabalho. Entendida como importante variável para avaliar as desigualdades de gênero, refere-se à participação da população ativa de mulheres, que inclui aquelas que estão empregadas e aquelas que estão desempregadas em busca de emprego. A participação das mulheres no mercado de trabalho é incorporada ao Gll em substituição às medidas de acesso a renda utilizadas no GDI e no GEM, por haver recebido muitas críticas como uma variável problemática (PERMANYER, 2013).

O PNUD (2010) reconhece que o novo indicador adotado também apresenta limitações importantes, principalmente quanto à segregação ocupacional no mercado de trabalho e às disparidades dos salários entre homens e mulheres, contudo argumenta que não há dados desagregados por sexo sobre renda para um número considerável de países, o que inviabiliza a realização de um índice que se pretende global.

A terceira dimensão constitutiva do Gll é o empoderamento, que agora passa a ser analisado a partir de dois indicadores, quais sejam a representação parlamentar e o nível educacional (PNUD, 2010).

Para a mensuração da representação parlamentar continua sendo utilizada a proporcionalidade de mulheres com assento no parlamento nacional, partindose da ideia de que "reflete a visibilidade das mulheres na liderança política e, em termos mais gerais, na sociedade" (PNUD, 2010, p.96). Para Permanyer (2013, p.3), a representação parlamentar "é uma medida aproximada, mas amplamente disponível, do acesso das mulheres ao poder"15.

No que se refere ao indicador de nível educacional, é mensurado por meio da proporcionalidade de mulheres como mais de 25 anos que tenham realizado pelo menos o nível educacional secundário. De acordo com o PNUD (2010), a importância desse indicador reside no fato de que o aumento no nível

15 Texto original: "is a crude, but widely available, measure of women's access to power". 
educacional tende a levar a um maior grau de autonomia das mulheres, posto que fortalece suas capacidades de refletir, questionar e agir sobre sua própria condição. Além disso, as mulheres que alcançam um nível educacional mais elevado teriam uma maior probabilidade de desempenhar trabalhos que thes deem satisfação, de cuidar de sua saúde e da saúde de sua família, de participar nos debates públicos e empreender iniciativas autônomas.

Percebe-se, portanto, que o Gll agrega variáveis que comparam a situação de homens e mulheres, como é o caso das dimensões de empoderamento e participação na força de trabalho, bem como variáveis que se aplicam unicamente às mulheres, quando avalia a saúde reprodutiva. Dessa forma, as três dimensões são agregadas de forma sintética, "uma vez que a consideração conjunta de empoderamento e desenvolvimento reflete complementariedades importantes" (UNDP, 2010, p.90) ${ }^{16}$.

\section{Limitações e ausências das dimensões utilizadas}

\section{Limitações das dimensões e indicadores utilizados}

Entre as críticas feitas acerca das dimensões escolhidas para a avaliação do empoderamento nos índices propostos pelo PNUD, destaca-se o fato de que a seleção dos indicadores é geralmente tendenciosa no sentido de mensurar o empoderamento das mulheres que estão em situação mais favorável. No que se refere à dimensão de participação política, por exemplo, tanto o GEM quanto o Gll utilizam a presença das mulheres no parlamento como indicador. No entanto, as instituições legislativas nacionais são espaços tradicionalmente ocupados por elites, por grupos com fortes redes de articulações econômicas e políticas, e com acesso a maiores níveis de educação formal (BETETA, 2006).

O mesmo ocorre no caso da dimensão de participação econômica e oportunidades profissionais utilizada pelo GEM, cujos indicadores baseiam-se na inclusão de mulheres em setores profissionais que requerem acesso a uma formação educacional específica e que geralmente remetem a uma posição de maior vantagem em termos econômicos. Assim como na dimensão de acesso a

16 Texto original: "since joint consideration of empowerment and development reflects important complementarities". 
renda, os indicadores utilizados são medidos exclusivamente no setor formal da economia, o que, segundo Kabeer (2003), denota um viés de classe na análise.

Dessa maneira, as desigualdades de gênero existentes nas dimensões política e econômica propostas pelo GEM e pelo Gll são mensuradas sem considerar o contexto das mulheres que integram os grupos mais vulneráveis do ponto de vista econômico e político. É nesses grupos em que possivelmente as disparidades sejam ainda mais aprofundadas pela interseccionalidade com outras dimensões de exclusão.

A superação dos limites postos pelos vieses resultantes dos indicadores utilizados trata-se de um desafio profundo, principalmente pelas dificuldades existentes em termos de acesso a dados estatísticos. Se a limitação dos dados existentes produzem um viés de classe nas análises realizadas em cada país, a não existência de dados em muitos países impede completamente a mensuração dos índices.

\begin{abstract}
A principal razão para isso é a indisponibilidade de informação sobre a participação feminina na renda e em posições de tomada de decisões econômicas (legislativas, administrativas, gerenciais, profissionais, etc.); esta falta de dados impede a estimativa do GEM em $60 \%$ e $90 \%$ dos países com médio e baixo desenvolvimento humano, respectivamente. Como resultado, esse índice composto não é somente enviesado no sentido de medir o empoderamento das mulheres em melhor situação em qualquer que seja o país, mas ele se torna uma medida relevante principalmente para os países com alto desenvolvimento humano (BETETA, 2006, p.223) ${ }^{17}$.
\end{abstract}

Aponta-se, portanto, a escassez de produção de dados válidos, especialmente que sejam desagregados por sexo e passíveis de comparação, a fim de permitir a composição de indicadores para utilização em escala mundial. Além disso, a produção de dados deve ter como pano de fundo a preocupação com os possíveis vieses resultantes dos enfoques definidos sobre os setores a serem analisados. Nesse sentido, "a inclusão de novos indicadores para medir o empoderamento das mulheres entre a população economicamente menos

\footnotetext{
17 Texto original: "The main reason for this is the unavailability of information on female share of income and of economic decision-making positions (legislators, officers, managers, professionals, etc.); this lack of data prevents the estimation of the GEM in $60 \%$ and $90 \%$ of medium and low human development countries, respectively. As a result, this composite index is not only biased towards measuring the empowerment of the better-off within any given country, but it remains a measure mainly relevant for high human development countries".
} 
privilegiada é uma necessidade urgente" (BETETA, 2006, p.229) ${ }^{18}$, assim como a produção de dados confiáveis sobre a proporção de mulheres em situação de pobreza e extrema pobreza, em grande medida indisponíveis, ou, quando disponíveis, comprometidos pela mensuração realizada por meio de pesquisas domésticas não individuais.

Entre as sugestões realizadas, destaca-se o uso de estatísticas acerca da participação das mulheres na força de trabalho, por se tratar de um dado já compilado pela Organização Internacional do Trabalho (OIT) e cada vez mais disponível em escala global e em condições de comparabilidade (BETETA, 2006). De fato, a participação das mulheres no mercado de trabalho foi incorporada à composição do Gll, em 2010, ainda que não como uma das variáveis da dimensão de empoderamento, posto que há questionamentos sobre em que medida tal indicador poderia ser relevante para a concepção de empoderamento. Além disso, entre os limites relacionados a esse indicador, aponta-se novamente o foco sobre os setores formais da economia, o que reforça a necessidade de pensar a produção estatística para além da esfera institucional estabelecida.

No que tange à participação política das mulheres, a escolha do indicador a partir dos assentos ocupados no parlamento nacional resulta justamente do fato se ser "um dos poucos indicadores amplamente disponíveis sobre representação política feminina" (BETETA, 2006, p.224) ${ }^{19}$ com uma forma de verificação objetiva, acesso simples e ampla comparabilidade. Se, por um lado, afirma-se a importância da equidade de gênero na representação política como fator que promove a legitimidade dos processos decisórios institucionais e a criação de modelos para meninas e mulheres (TREMBLAY, 1998), por outro lado, questiona-se em que medida é possível utilizar de forma comparável a presença de mulheres nos legislativos nacionais como uma medida de empoderamento, visto que tal representatividade é provavelmente determinada em maior medida pelo funcionamento do sistema político e eleitoral do que em função de características socioeconômicas e culturais (GOETZ, 2004).

\footnotetext{
18 Texto original: "the inclusion of new indicators measuring women's empowerment among the less economically advantaged population is an urgent necessity".

19 Texto original: "one of the few widely available indicators on female political representation".
} 
O uso da porcentagem de mulheres em parlamentos como uma medida de empoderamento pode ser enganoso, a não ser que seja aceito 0 argumento de que a presença feminina relativa nos parlamentos nacionais tem a capacidade de empoderar mulheres independente dos meios pelos quais as representantes foram colocadas nesse lugar (BETETA, 2006, p.225) 20.

Mais do que ocupar espaços políticos institucionais, o empoderamento traduz-se pela capacidade de influência das mulheres como sujeito político sobre os processos decisórios. Goetz (2004, p.2) defende que é preciso maior atenção para a efetividade da atuação política das mulheres, que ela define como:

\begin{abstract}
A habilidade de usar a voz para politizar questões de interesse das mulheres, usar a influência eleitoral para pressionar demandas sobre tomadores/as de decisões, para provocar uma melhor responsividade do setor público sobre suas necessidades, e fortalecer os compromissos constitucionais com relação a direitos iguais para as mulheres ${ }^{21}$.
\end{abstract}

No que se refere à atuação política das mulheres no âmbito parlamentar, identifica-se uma série de obstáculos que dificultam sua efetividade. De acordo com Reynolds (1999), nos países em desenvolvimento há uma forte correlação entre o acesso das mulheres à política institucional e sua origem de elite familiar, o que denota um distanciamento dessas mulheres da experiência dos movimentos feministas.

Para Vijayalakshmi (2002), pode ser identificada uma ausência de preocupações de gênero na atuação legislativa de mulheres, em função, entre outros fatores, da multiplicidade de identidades que compõem tal atuação - como filiação partidária e pertencimento de classe - e que se sobrepõem a uma possível agenda feminista. De acordo com o relatório Gender Equality: Striving for Justice in an Unequal World, publicado pelo Instituto de Pesquisa das Nações Unidas para o Desenvolvimento Social (UNRISD, 2005), os partidos políticos tendem a descartar feministas para evitar um comprometimento eleitoral, logo as mulheres que atuam na carreira política tendem a não defender uma agenda

20 Texto original: "The use of the percentage of women in parliaments as a measure of empowerment may be misleading, unless it can be argued that women's relative presence in national parliament has the capacity to empower women regardless of the means by which representatives were put in office".

21 Texto original: "The ability to use voice to politicize issues of concern to women, to use electoral leverage to press demands on decision-makers, to trigger better responsiveness from the public sector to their needs, and better enforcement of constitutional commitments to women's equal rights". 
feminista e possuem, geralmente, vínculos frágeis com organizações de mulheres.

De acordo com o UNRISD (2005), são poucos os estudos existentes acerca do impacto da atuação política das mulheres em países em desenvolvimento, em certa medida por causa do baixo número de mulheres que ocuparam um assento legislativo por tempo suficiente para ter possibilidade de impactos significativos sobre as políticas. Argumenta-se, portanto, que não há entendimento suficiente acerca da efetividade da atuação política das mulheres. Nesse sentido, as incertezas em torno da relação existente entre a proporcionalidade de mulheres nos parlamentos nacionais e o impacto resultante dessa representatividade sobre o empoderamento das mulheres seria um motivo forte para sugerir modificações quanto à utilização desse indicador.

A relação entre representação formal de mulheres na política, a real
representação das mulheres e empoderamento feminino é ainda
confusa. Por essa razão, indicadores para além da representação
política formal devem ser explorados, a fim de serem coletados,
relatados e eventualmente incorporados em alguma medida de
empoderamento de gênero (BETETA, 2006, p.228)

Entre as recomendações de adoção de outros indicadores para mensurar a efetividade da participação política feminina, figura como elemento central o fortalecimento dos movimentos de mulheres (REYNOLDS, 1999; NAZ, 2002; WELDON, 2002; VIJAYALAKSHMI, 2002; BAUER, 2004). A força dos movimentos de mulheres, principalmente dos movimentos feministas, é um importante canal de comunicação sobre as demandas das mulheres em um país. Além de medida relevante sobre a efetividade da participação política das mulheres, são os movimentos os primeiros a pautarem questões específicas para as mulheres, como violência doméstica, o direito ao divórcio e ao aborto, entre outros. Junto com a relevância do conteúdo das agendas feministas, a ação a partir de diversas estratégias, como protestos, advocacy e campanhas, contribuem para influenciar a consciência e as atitudes acerca da equidade de gênero. Nesse sentido, de acordo com Weldon (2002), a atuação de um

22 Texto original: "The relationship between women's formal representation in politics, the actual representation of women and female empowerment is still unclear. For this reason, indicators beyond formal political representation should be explored, in order to be collected, reported and eventually incorporated in some measurement of gender empowerment". 
movimento de mulheres forte e autônomo explica melhor a adoção de políticas públicas para as mulheres do que a presença feminina no parlamento.

\section{Ausência de dimensões e indicadores}

No debate em torno dos elementos constitutivos dos índices propostos pelo PNUD para mensuração do empoderamento das mulheres são diversas as recomendações sobre quais as variáveis que devem ser consideradas para chegar a indicadores que traduzam de forma mais aproximada a realidade global. Embora reconheça-se a importância das dimensões incorporadas ao GEM e ao Gll, mesmo considerando as ressalvas em termos de suas limitações, aponta-se a necessidade de inclusão de outros elementos fundamentais para o conceito de empoderamento (PILLARISETTI; MCGILLIVRAY, 1998; CHARMES; WIERINGA, 2003; BETETA, 2006; PERMANYER, 2013).

Avanços nas dimensões de poder político e econômico das mulheres são valiosos para que ocorram transformações quanto às relações de gênero. Contudo mudanças nessas dimensões não são condições necessárias nem suficientes para o empoderamento das mulheres. Um país poderia, por exemplo, apresentar mudanças significativas, como redução da violência de gênero ou maior proteção de direitos das mulheres, sem necessariamente ter passado por transformações nas dimensões de poder político e econômico apresentadas (CHARMES; WIERINGA, 2003).

Charmes e Wieringa (2003) desenvolveram uma matriz sobre empoderamento das mulheres que se propõe conectar seis diferentes esferas e níveis em sua análise. Esse instrumento foi resultado de um esforço para lançar um Índice de Desigualdade de Gênero para África (AGDI), em nome da Comissão Econômica das Nações Unidas para África (UNECA), a partir das lacunas identificadas na análise do GDI e do GEM. As seis esferas identificadas para a matriz foram: física, sociocultural, religiosa, política, legal e econômica, enquanto os seis níveis foram: individual, doméstico, comunitário, estatal, regional e global. Para a autora e o autor da matriz, o GEM apresenta falhas no que se refere à inclusão de questões legais, culturais e religiosas, além de questões relacionadas ao corpo e à sexualidade; com relação aos níveis de análise, as lacunas apontadas dizem respeito ao nível individual, doméstico e 
comunitário, que não são considerados no índice.

A incorporação de todas as esferas e níveis propostos em um único índice poderia ser dificultada pela escassez quanto à disponibilidade de dados estatísticos confiáveis, bem como pelos limites operacionais de se trabalhar com um grande número de dimensões, sob o risco de se perder o foco acerca das variáveis trabalhadas. Beteta (2006) sugere a inclusão da esfera da autonomia física e do nível doméstico junto às dimensões trabalhadas pelo GEM, em função de sua importância para o processo de empoderamento das mulheres. Além disso, propõe a criação de um novo indicador, referente ao ambiente, que favorece o empoderamento de gênero, com base nas esferas legal e sociocultural recomendadas pela matriz de Charmes e Wieringa (2003), juntamente com uma dimensão de fortalecimento dos movimentos de mulheres.

O nível doméstico é considerado como uma das grandes lacunas dos índices propostos pelo PNUD, posto que a esfera privada é uma dimensão tradicionalmente ocupada pelas mulheres e de grande relevância para analisar o processo de empoderamento (CHARMES; WIERINGA, 2003; BETETA, 2006). Embora o componente de acesso a renda utilizado no GEM tenha sido considerado como um indicador de autonomia e maior controle sobre decisões domésticas (WORLD BANK, 2001), foram muitas as controvérsias em torno dessa variável, principalmente sobre os procedimentos utilizados para sua mensuração, bem como o uso de níveis de renda em vez de distribuição de renda, o que, para a análise de empoderamento, pode levar a conclusões questionáveis.

Entre as recomendações realizadas acerca da utilização de indicadores para a mensuração do empoderamento das mulheres no âmbito doméstico, destacam-se as pesquisas de uso de tempo (TUS) e as pesquisas de demografia e saúde (DHS).

As TUS já são utilizadas nos Relatórios de Desenvolvimento Humano publicados pelo PNUD, mas não são incorporadas aos índices de gênero; tais pesquisas estimam o tempo dedicado por homens e mulheres, ao longo do dia, para as atividades da esfera doméstica e do âmbito do mercado, bem como a distribuição percentual dos tipos de atividades realizadas por cada grupo. Para Beteta (2006, p.230), "novos indicadores sobre empoderamento feminino no 
nível doméstico podem e devem ser construídos usando informações dessas pesquisas"23.

A base de dados das DHS oferece indicadores mais diretos sobre o poder de decisão das mulheres na esfera doméstica, por meio de informações acerca do controle sobre os gastos do próprio dinheiro e sobre decisões específicas referentes a, por exemplo, o cuidado de sua própria saúde e visita a familiares e amigos/as. Fontes como as DHS podem também contribuir para a mensuração de uma dimensão fundamental para o empoderamento das mulheres e que tem estado ausente dos índices apresentados: o poder de decisão sobre seu próprio corpo e sua sexualidade. A liberdade de escolha sobre ter ou não ter filhos é "um dos elementos centrais do empoderamento ou desempoderamento das mulheres"24 (BETETA, 2006, p.231) e pode ser mensurada pelo uso de métodos contraceptivos, o direito ao aborto seguro ou a diferença entre a taxa de fertilidade desejada e a existente.

Apesar das possibilidades de mensuração apresentadas no que se refere à autonomia das mulheres sobre seu próprio corpo e sexualidade, percebe-se a dificuldade no reconhecimento de tais elementos como parte fundamental do processo de empoderamento das mulheres, quando se observa que no Gll foi incluída apenas a dimensão de saúde reprodutiva, medida pela mortalidade materna e taxa de fecundidade adolescente. A priorização da saúde reprodutiva em detrimento do reconhecimento dos direitos sexuais das mulheres é uma preocupação dos movimentos feministas, que tradicionalmente enfrentam politicamente as forças conservadoras que se opõem aos direitos das mulheres, principalmente no que se refere à vivência de sua sexualidade de forma autônoma. Corrêa, Alves e Januzzi (2006, p.40) tratam dos embates existentes no âmbito da política internacional quanto aos direitos sexuais das mulheres:

Desde os processos de revisão +5 (1998-1999), tornar-se-ia cada vez
mais difícil aprovar em documentos intergovernamentais linguagem
relativa à saúde sexual, direitos reprodutivos e, mais especialmente, a
direitos sexuais. As negociações de Pequim +10, em 2005 , ilustram de
maneira contundente esta dificuldade, pois, nesta ocasião, a
delegação americana bloqueou a expressão "direitos humanos das
mulheres" na declaração política da $59^{a}$ Sessão da Comissão para o

${ }^{23}$ Texto original: "new indicators on female empowerment at the household level could and should be constructed using information from these surveys".

${ }^{24}$ Texto original: "one of the key elements of women's empowerment or disempowerment". 
Status da Mulher, argumentando temer que esta implicasse a criação de novos direitos e constituísse um eufemismo para direito ao aborto e direitos sexuais.

É fundamental, portanto, reconhecer que, para além das limitações metodológicas e operacionais existentes na formulação dos indicadores para 0 monitoramento de políticas de promoção de equidade de gênero, existem as limitações da política internacional que refletem as disputas em torno do reconhecimento das mulheres como sujeitos de direitos. Nesse sentido, duas importantes dimensões são sugeridas para a análise dos índices de empoderamento: a esfera legal de proteção aos direitos das mulheres e a força dos movimentos organizados por mulheres.

A existência de um marco legal e regulatório é um dos elementos constitutivos de um ambiente favorável ao empoderamento feminino. A fim de avaliar essa dimensão, propõe-se dois grupos de variáveis: um referente aos instrumentos internacionais disponíveis e o outro com relação à equidade de direitos entre homens e mulheres (BETETA, 2006).

Entre os instrumentos internacionais disponíveis, destaca-se a Plataforma de Ação de Pequim, resultante da Conferência Mundial de Mulheres de 1995, promovida pela ONU, e a Convenção sobre a Eliminação de todas as formas de Discriminação contra as Mulheres (CEDAW). A operacionalização dessa variável pode ser realizada por meio da identificação da ratificação dos instrumentos e principalmente por meio da sua implementação, que deve ser analisada para além do compromisso formal, pela observação da adoção de políticas nacionais e da criação de organismos específicos com alocação de orçamento suficiente (BETETA, 2006).

Para a mensuração da esfera de equidade de direitos, o respeito aos direitos das mulheres e o nível de tolerância governamental à discriminação contra as mulheres devem ser observados. Garantias como licença maternidade, trabalhar livre de assédio moral, direito à herança, a obter passaporte, a conferir cidadania para filhos/as ou companheiros/as, a solicitar divórcio, a trabalhar em áreas tradicionalmente reservadas aos homens, são alguns dos elementos considerados para a elaboração de índices existentes com base em uma perspectiva de direitos humanos (BETETA, 2006). 
Um dos questionamentos possíveis quando se trata da escolha em torno das garantias de direitos humanos que devem ser consideradas para a avaliação do empoderamento das mulheres diz respeito aos pressupostos socioculturais. Embora, de acordo com o PNUD (1995, p.83), "o GEM não tenha a intenção de ser um índice prescritivo, com o intuito de estabelecer normas culturais universais" 25 , os indicadores escolhidos bem como a forma de mensuração podem desconsiderar fatores históricos e culturais que incidem sobre os elementos propostos e acabar beneficiando alguns países em detrimento de outros no que se refere à performance no índice.

O impacto político do GEM é questionado em função da pouca repercussão que teve, bem como das limitações quanto ao valor informacional e empírico trazido para as análises de gênero, posto que "não reflete adequadamente as dimensões de desigualdade de gênero nem em países em desenvolvimento, nem em nações desenvolvidas"26 (SCHULLER, 2006, p.177). Enquanto Schuller (2006) afirma que nem mesmo nos relatórios de desenvolvimento humano nacionais e subnacionais os indicadores foram utilizados como base para uma análise significativa acerca das inequidades de gênero, o PNUD (2005) destaca o exemplo de países como a Coréia do Sul, onde o GEM foi utilizado de forma estratégica para pressionar o governo, que respondeu com ações em prol de uma maior representação feminina nos setores político e econômico.

A publicação do Gll em 2010, mais do que substituir os primeiros índices que haviam sido bastante criticados, contribuiu ao debate sobre a mensuração das desigualdades de gênero "por meio da incorporação de conceitos e dimensões que não foram utilizados anteriormente no âmbito global" (PERMANYER, 2013, p.2) ${ }^{27}$. No entanto, o Gll responde somente a algumas das críticas levantadas em torno dos indicadores propostos anteriormente (KLASEN; SCHULER, 2011).

\footnotetext{
25 Texto original: "the GEM is not meant to be a prescriptive index, with the intent of setting universal cultural norms".

${ }^{26}$ Texto original: "do not adequately reflect gender inequality dimensions neither in developing countries, nor in developed nations".

${ }^{27}$ Texto original: "by incorporating concepts and dimensions that had not been used before at the global level".
} 
Para além das dimensões e indicadores que constituem os índices propostos pelo PNUD, como aqui discutido, destaca-se, entre as críticas realizadas sobre o Gll, a complexidade apresentada em termos de sua operacionalização e interpretação. Dessa forma, para que possa servir ao monitoramento de políticas públicas e como instrumento de advocacy, é importante que a utilização do índice seja acessível não somente a acadêmicos/as especializados/as, mas também a organizações da sociedade civil e organismos subnacionais, atores que desempenham papel fundamental na implementação e avaliação das políticas públicas.

\section{Considerações finais}

Os avanços ocorridos nas últimas décadas em relação ao reconhecimento das desigualdades de gênero como um problema global são bastante significativos, assim como os esforços mais recentes no sentido de incorporar o empoderamento das mulheres como um elemento central para a agenda internacional de desenvolvimento.

No entanto, apesar da existência de compromissos internacionais relevantes, a articulação das questões de gênero à implementação das políticas é imprecisa e influenciada, em grande medida, pelo contexto político e econômico em que se insere. As maneiras com que os conceitos vão sendo incorporados e apropriados no âmbito da política internacional não fogem a isso e no caso do uso do conceito de empoderamento pelo PNUD pode-se perceber a influência exercida pelas perspectivas de desenvolvimento vigentes, bem como diversas abordagens em torno da concepção de poder, nem todas de acordo com as demandas priorizadas pelos movimentos feministas.

Entende-se que a produção de conhecimento também é política. Para onde se olha e quais elementos são considerados dizem muito sobre o que importa e sobre o que é invisibilizado. A falta de dados desagregados por sexo, raça, etnia, geração e outras tantas variáveis fundamentais para o conhecimento das mais diversas realidades das mulheres denuncia o lugar político que ocupam e o pouco investimento material e intelectual dedicado a conhecer o que está nas margens, o que não é considerado prioritário. 
As formas de conhecer determinam, em grande medida, as possibilidades de atuação. Por isso, para que as políticas públicas cheguem aonde mais se necessita e de forma mais efetiva, é preciso que os processos de elaboração, implementação e monitoramento dialoguem também com as vivências das mulheres que estão distantes dos espaços formais de poder.

\section{Referências bibliográficas}

ALLEN, Amy. Rethinking power. Hypatia, v. 13, n. 1, p. 21-40, 1998.

BARDHAN, Kalpana; KLASEN, Stephan. On UNDP's revisions to the GenderRelated Development Index. Journal of Human Development, v. 1, n. 2, p. 191195, 2000.

BATLIWALA, Srilatha. The Meaning of Women's Empowerment: new concepts from action. In: SEN, Gita; Germain, Adrienne; Chen, Lincoln (eds.). Population policies reconsidered: health, empowerment and rights. Boston: Harvard University Press, 1994, p. 127-138.

BAUER, Gretchen. The hand that stirs the pot can also run the country: electing women to parliament in Namibia. Journal of Modern African Studies, v.42, n.4, p.479-509, 2004.

BETETA, Hanny Cueva. What is missing in measures of Women's Empowerment? Journal of Human Development, v.7, n.2, p. 221-241, 2006.

BUTLER, Judith. Performativity, precarity and sexual politics. Revista de Antropología Iberoamericana, v.4, n.3, pp. i-xiii, 2009.

CHARMES, Jacques; WIERINGA, Saskia. Measuring women's empowerment: an assessment of the Gender-related Development Index and the Gender Empowerment Measure. Journal of Human Development, v.4, n.3, p.419-435, 2003.

CORRÊA, Sônia; ALVES, José Eustáquio; JANNUZZI, Paulo. Direitos e saúde sexual e reprodutiva: marco teórico-conceitual e sistema de indicadores. In: CAVENAGHI, Suzana (org.). Indicadores municipais de saúde sexual e reprodutiva. Rio de Janeiro: ABEP, Brasília: UNFPA, 2006, p. 27-62.

FRASER, Nancy. A justiça social na globalização: redistribuição, reconhecimento e participação. Revista Crítica de Ciências Sociais, v.1 n.63, p. 7-20, 2002.

FRASER, Nancy. Da redistribuição ao reconhecimento? Dilemas da justiça numa era pós-socialista. Cadernos de Campo, v.15, n. 14/15, p. 231-239, 2006. 
FRASER, Nancy. O Feminismo, o capitalismo e a astúcia da história. Mediações, Londrina, v.14, n.2, p.11-33, 2009.

GOETZ, Anne Marrie. Women's education and political participation. Background paper prepared for the Education for All Global Monitoring Report 2003/4. Paris: UNESCO, 2004.

HARTSOCK, Nancy. Money, sex and power: toward a feminist historical materialism. Nova York: Longman, 1983.

KABEER, Naila. Resources, agency, achievements: reflections on the measurement of women's empowerment. In: SISAK, Anne (ed.). Discussing women's empowerment: theory and practice. Estocolmo: Swedish International Development Agency, 2001, p. 17-59.

KABEER, Naila. Gender mainstreaming in poverty eradication and the millennium development goals: a handbook for policy-makers and other stakeholders. Londres: Commonwealth Secretariat, 2003.

KLASEN, Stephan; SCHULLER, Dana. Reforming the Gender-Related Development Index and the Gender Empowerment Measure: implementing some specific proposals. Feminist Economics, v. 17, n.1, p.1-30, 2011.

KROLØKKE, Charlotte; SøRENSEN, Ann Scott. Three waves of feminism: from suffragettes to grrls. In: KROLØKKE, Charlotte; SØRENSEN, Anne Scott. Gender communication theories \& analyses: from silence to performance. Thousand Oaks: SAGE Publications, 2006, p. 1- 24.

LUGONES, María. Colonialidad y género. Tabula Rasa, n.9, p.73-101, 2008.

MOSER, Caroline. Gender planning in the third world: meeting practical and strategic gender needs. World Development, v.17, n.11, p. 1799-1825, 1989.

NAZ, Antonia. The political participation of women legislators in Congress. Review of Women's Studies, v. 13, n.1/2, p.13-48, 2002.

PERMANYER, Iñaki. A critical assessment of the UNDP's Gender Inequality Index. Feminist Economics, v.19, n.2, p.1-32, 2013.

PILLARISETTI, J. Ram; MCGILLIVRAY, Mark. Human development and gender empowerment: methodological and measurement issues. Development Policy Review, v.16, n.2, p.197-203, 1998.

PNUD. Relatório de Desenvolvimento Humano 2010. A verdadeira riqueza das nações: vias para o desenvolvimento humano. IPAD: Lisboa, 2010.

REYNOLDS, Andrew. Women in African legislatures and executives: the slow climb to power. Joanesburgo: Electoral Institute of South Africa, 1999. 
SANTOS, Giselle. Gênero, desenvolvimento e Programa Bolsa Família: direitos reprodutivos, trabalho e projetos de vida de mulheres do Coque. Tese de Doutorado em Antropologia, Universidade Federal de Pernambuco, 2014.

SARDENBERG, Cecília. Liberal vs. Liberating Empowerment: conceptualising empowerment from a Latin American feminist perspective. Pathways Working Paper 7. Brighton: Pathways of Empowerment, 2009a.

SARDENBERG, Cecília. Conceituando "empoderamento" na perspectiva feminista. 2012. Disponível em: <http://repositorio.ufba.br/ri/handle/ri/6848> Acessado em 4 de agosto de 2017.

SCHULER, Dana. The uses and misuses of the Gender-related Development Index and Gender Empowerment Measure: a review of the literature. Journal of Human Development, v.7, n. 2, p. 161-181, 2006.

SPIVAK, Gayatri. Pode o subalterno falar? Belo Horizonte: Editora UFMG, 2010.

SQUIRES, Judith. Gender in political theory. Cambridge: Polity Press, 1999.

TINKER, Irene; JAQUETE, Jane. The UN Decade for Women: its impact and legacy. World Development, v. 15, n. 3. p. 419-427, 1987.

TREMBLAY, Manon. Do female MPs substantively represent women? A study of legislative behaviour in Canada's 35th parliament. Canadian Journal of Political Science, v. 31, n.3, p. 435-465, 1998.

UNDP. Human Development Report 1995. Oxford University Press: Nova York, 1995.

UNDP. Human Development Report 2010. The real wealth of nations: pathways to human development. Palgrave: Nova York, 2010.

UNRISD. Gender equality: striving for justice in an unequal world. UNDP: Genebra, 2005.

VÁZQUEZ, María de la Fuente. Poder y feminismo: elementos para una teoría política. Tese de Doutorado em Ciência Política. Universitat Autònoma de Barcelona, 2013a.

VÁZQUEZ, María de la Fuente. Power over, power to and power with: 'third wave' revisions of feminist frames of power. ECPG Congress. Barcelona, 2013b.

VIJAYALAKSHMI, V. Gender, accountability and political representation in local government. Working Paper, n. 102, Institute for Social and Economic Change, Bangalore, 2002.

WELDON, S. Laurel. Protest, policy and the problem of violence against women: a cross-national comparison. Pittsburgh: University of Pittsburgh Press, 2002. 
WORLD BANK. Engendering development through gender equality in rights, resources and voice. Washington: Oxford University Press, 2001.

ZABALA, Idoye. El Banco Mundial y su influencia en las mujeres y en las relaciones de género. Cuadernos de Trabajo de Hegoa. Bilbao: Universidad del País Vasco, 2006.

Recebido em 23 de abril de 2017. Aprovado em 04 de agosto de 2017. 